\title{
Optimization of Cutting Force and Surface Roughness Based on Taguchi Technique for AA6061
}

\author{
Elssawi Yahya, G.F. Ding \\ School of Mechanical Engineering \\ Southwest Jiao tong University \\ Chengdu, China
}

\author{
Elssawi Yahya \\ School of Mechanical Engineering \\ Sudan University of Science and Technology \\ Khartoum, Sudan
}

\author{
Hashim AIi salim \\ School of Industrial Engineering \\ Sudan University of Science and Technology \\ Khartoum, Sudan
}

\begin{abstract}
Optimization of machining parameters has great concerned in manufacturing environments, there for in this study cutting force and surface roughness are optimized based on machining parameters. Many researchers have established the relationship between the surface roughness and machining parameters, but less attention has been paid to tool shape and geometry, in this study tool flute is first time used as machining factor beside cutting speed, depth of cut and feed rate. Response Surface Method and analysis of variance are adopted to establish the relationship of machining parameters to the surface roughness and cutting force using Taguchi technique. Optimization of cutting force and surface roughness are simultaneously adopted, either by optimized cutting force or surface roughness. The minimum surface roughness obtained is $0.2398 \mu \mathrm{m}$ with corresponding cutting parameter is $12.01 \mathrm{~N}$.
\end{abstract}

Keywords-cutting force; surface roughness; optimizations; Taguchi method; machining parameters; significant analysis

\section{INTRODUCTION}

Metal cutting is one of the important processes used widely in manufacturing and engineering industries. Study of metal cutting focuses on the features of tools and machine parameter settings, which influencing process efficiency and output quality characteristics. A significant improvement in process efficiency may be obtained by process parameter optimization that identifies and determines the regions of critical process [1], which mentioned control factors leading to desired outputs or responses with acceptable variations ensuring a lower cost of manufacturing. The technology of metal cutting has grown substantially over time owing to the contribution from many branches of engineering with a common goal of achieving higher machining process efficiency. Selection of optimal machining condition(s) is a key factor in achieving this condition [2]. In multi-stage metal cutting operation, the manufacturer seeks to set the processrelated controllable variable(s) at their optimal operating conditions with minimum effect of uncontrollable or noise variables on the levels and variability in the output(s). Several modeling techniques proposed and implemented are based on statistical regression [3], artificial neural network [4] and fuzzy set theory [5]. Optimization tools and techniques proposed are also based on Taguchi method [6], response surface design [7], mathematical programming [8], genetic algorithm [9], tabu search [10], and simulated annealing [11]. Despite of numerous studies on process optimization problems, there exists no universal input-output and in process parameter relationship model, which is applicable to all kinds of metal cutting processes [12]. Luong \& Spedding [13] claim a lack of basic mathematical model that can predict cutting behavior over a wide range of cutting conditions. Optimization techniques also have certain constraints, assumptions and limitations for implementation in real-life cutting process problems as mentioned in [14 - 17].

In this study, AA6061 aluminum alloy is selected as a work piece material. This type of aluminum is heat-treatable, and it has the best qualities of aluminum. Good surface of this type of aluminum would improve both appearance and corrosion resistance. Therefore, applications of this grade are used for a wide variety of products and applications from truck bodies and frames to screw machine parts and structural components. Experimental work is carried out and surface roughness is measured. Cutting parameters used in this study are cutting speed, depth of cut, feed rate and tool flutes. Tool flutes is a new factor added in this study. Taguchi method is selected in this study to optimize the machining parameters.

\section{Methodologies}

The aim of this application is to optimize machining parameters for cutting force and surface roughness, quadratic mathematical model Equations (1) is selected to estimate optimization results for cutting force and surface roughness responses. This model is suitable since no information about the function type.

$$
\hat{y}=b_{0}+\sum_{i=1}^{n} b_{i} x_{i}+\sum_{i=1}^{n} b_{i i} x_{i}^{2}+\sum_{i=1}^{n-1} \sum_{j=i+1}^{n} b_{i j} x_{i} x_{j}+\varepsilon
$$

Where $\hat{\mathrm{y}}$ is predicted value (response); $b_{0}, b_{i}, b_{i i}$ and $b_{i j}$ are regression coefficients; $x_{i}, x_{j}$ are independent variables and $\varepsilon$ is the error. 


\section{EXPERIMENTAL WORKS}

In this work, Taguchi technique is used to express the significant of the machining parameters based on surface roughness and cutting force. The first step is how to choose the appropriate orthogonal array that affects the experiment plan and accuracy of the statistical analysis [18], OA L27 orthogonal array is selected.

Fig.1 shows the optimization flow process. The experimental work conducted on $\mathrm{CNC}$ machine, cutting force measured by sensors conducted to the work piece and surface roughness measured using surface roughness device. In this study an attempt is carried out to optimize machined surface (finishing) by controlling the input machining parameters. Minitab software is adopted to optimize responses using inner algorithm.

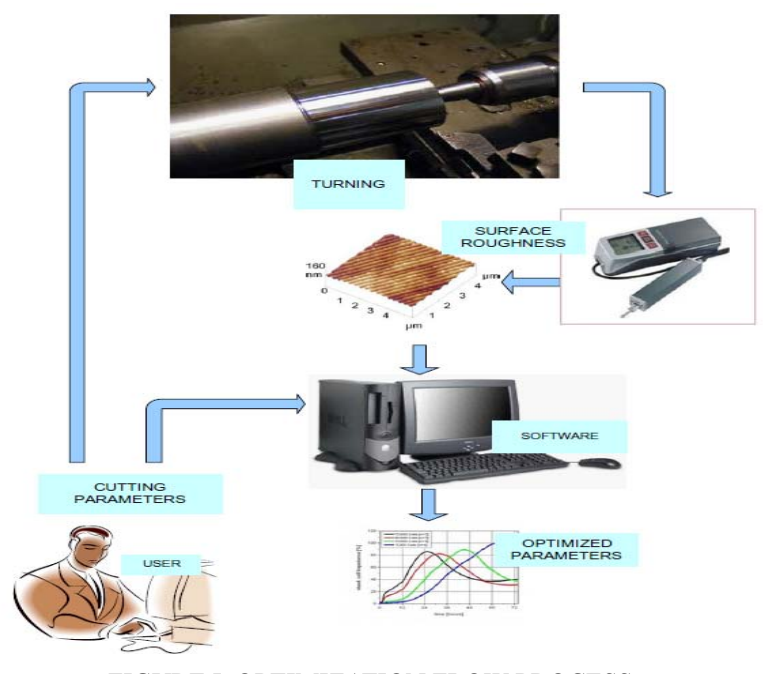

FIGURE I. OPTIMIZATION FLOW PROCESS

\section{RESUlTS}

Experimental results are carried out based on Taguchi design and orthogonal array (OA L27). Minitab software is applied to obtain the optimized values for responses based on P-values. Significant parameters are carried out at $95 \%$ confidence intervals. Equations $1 \& 2$ are expressing the predictive values of surface roughness and cutting force respectively.

$$
\begin{gathered}
R_{a}=0.437+0.086 d-0.132 z+0.153 z^{2} \\
F_{c}=9.54-3.08 v-3.66 d-2.08 f-1.31 z+1.63 f^{2}+1.15 z^{2}
\end{gathered}
$$

Where $\mathrm{Ra}$ is surface roughness, Fc cutting force, and the others factors are machining parameters, these are: $d$ depth of cut, $\mathrm{v}$ cutting speed, $\mathrm{f}$ feed rate and $\mathrm{z}$ is the tool flutes.

From the above equations, surface roughness and cutting force can be evaluated. Based on the results obtained nonlinear equations have the same routes when the tool has only two flutes only, and only valid in these limits.

Based on the results achieved surface roughness has only two significant cutting parameters, depth of cut and tool flutes as show in equation (2). All cutting parameters used in this study are significantly affected cutting force as shown in equation (3). The above equations are evaluated in the previous studies which show the reliability is limited, when the number of tool flutes is only two. There for an optimization of the machining parameters based on surface roughness or cutting force is an essential topic. In this study, an attempt carried out for optimization of machining parameters based on both cutting force and surface roughness simultaneously.

\section{OPTIMIZATIONS}

Optimization of machining parameters could be evaluated for surface roughness and cutting force simultaneously, there for Figures $2 \& 3$ show optimized machining values. In this stage controlling of surface roughness could lead to control the cutting force and vice versa. Figure 2 shows Minitab software output in optimized surface roughness 0.2398 with corresponding cutting force $12.02 \mathrm{~N}$ using inner algorithm. Optimizations desirability function is 0.00 which means the optimized value is far from the target, the target value selected randomly in this study is 0.0620 . This means from experimental work, we cannot get real value of surface roughness less than 0.2398 which is so far from the selected target of 0.0620 .

Usually optimize target is preferred the minimum values of responses in this types of applications, for surface roughness to express the robust technique, while for cutting force to reduce the power consumption. Figure 3 shows optimized minimum cutting force $2.72 \mathrm{~N}$ for target cutting force $4 \mathrm{~N}$ with the same desirability value 0.00 , cutting speed and feed rate are increased to $5000 \mathrm{rpm}$ and $0.15 \mathrm{~mm}$.

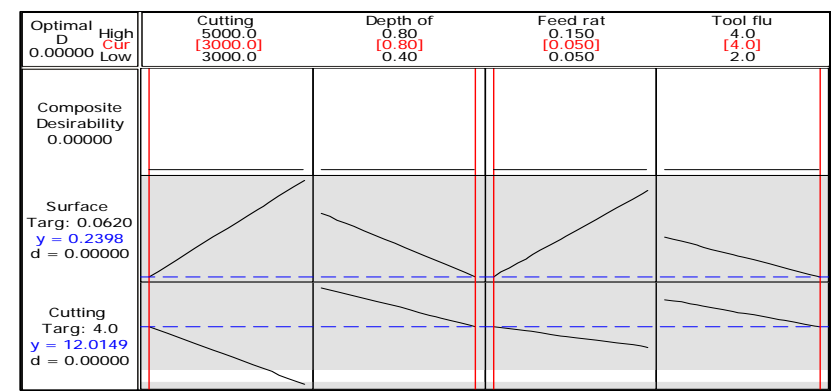

FIGURE II. OPTIMIZATION RESULTS BASED ON MINIMUM SURFACE ROUGHNESS.

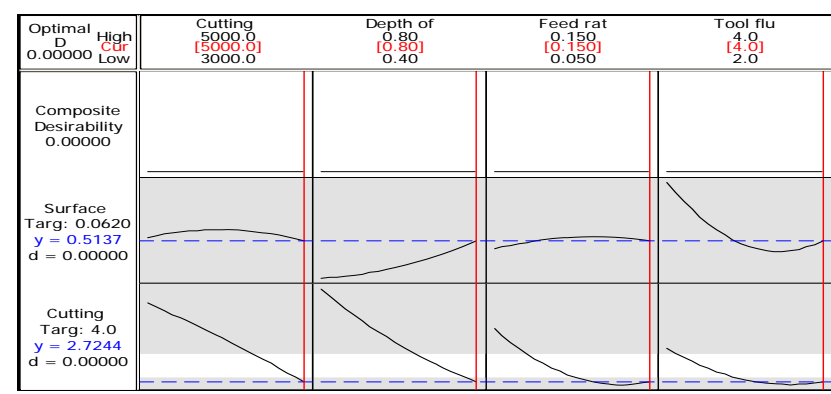

FIGURE III. OPTIMIZATION RESULTS BASED ON MINIMUM CUTTING FORCE. 


\section{VERIFICATIONS}

In order to verify the optimization results, experimental work is carried out based on optimized machining parameters values. Table 1 shows the verifications of the optimized results for surface roughness, and table 2 shows the corresponding cutting force verifications. The error values in surface roughness optimization are more accepted than cutting force.

\section{TABLE I. VERIFICATION OF SURFACE ROUGHNESS OPTIMIZED} RESULTS.

\begin{tabular}{|c|c|c|c|c|c|c|c|}
\hline $\begin{array}{l}\text { e } \\
\text { st } \\
\mathrm{N}\end{array}$ & $\begin{array}{l}\text { Cutti } \\
\text { ng } \\
\text { speed } \\
\text { (rpm) }\end{array}$ & $\begin{array}{l}\text { Depth } \\
\text { of cut } \\
(\mathrm{mm})\end{array}$ & $\begin{array}{l}\text { Fee } \\
\mathrm{d} \\
\text { rate } \\
(\mathrm{m} \\
\mathrm{m})\end{array}$ & $\begin{array}{l}\text { To } \\
\text { ol } \\
\text { fl } \\
\text { ut } \\
\text { es }\end{array}$ & $\begin{array}{l}\text { Optim } \\
\text { ization } \\
\text { results } \\
(\mu \mathrm{m})\end{array}$ & $\begin{array}{l}\text { Experi } \\
\text { mental } \\
\text { results } \\
(\mu \mathrm{m})\end{array}$ & $\begin{array}{l}\text { Erro } \\
r \\
(\mu \mathrm{m} \\
)\end{array}$ \\
\hline 1 & 3000 & 0.8 & 0.05 & 4 & 0.2398 & 0.2277 & $\begin{array}{l}+ \\
0.01 \\
21\end{array}$ \\
\hline 2 & 3000 & 0.8 & 0.05 & 4 & 0.2398 & 0.2247 & + \\
\hline 3 & 3000 & 0.8 & 0.05 & 4 & 0.2398 & 0.2500 & $\begin{array}{l}0.01 \\
51 \\
- \\
0.01 \\
02\end{array}$ \\
\hline
\end{tabular}

TABLE II. CUTTING FORCES VERIFICATIONS CORRESPONDING TO OPTIMIZED RESULTS.

\begin{tabular}{|c|c|c|c|c|c|c|c|}
\hline $\begin{array}{l}\text { Te } \\
\text { st } \\
\mathrm{N} \\
\text { o. }\end{array}$ & $\begin{array}{l}\text { Cuttin } \\
\text { g } \\
\text { speed } \\
\text { (rpm) }\end{array}$ & $\begin{array}{l}\text { Dept } \\
h \text { of } \\
\text { cut } \\
\text { ( } \mathrm{mm} \\
\text { ) }\end{array}$ & $\begin{array}{l}\text { Fee } \\
\mathrm{d} \\
\text { rate } \\
(\mathrm{mm} \\
) \\
\end{array}$ & $\begin{array}{l}\text { To } \\
\text { ol } \\
\text { flu } \\
\text { tes }\end{array}$ & $\begin{array}{l}\text { Optimi } \\
\text { zation } \\
\text { results } \\
\text { (N) }\end{array}$ & $\begin{array}{l}\text { Experi } \\
\text { mental } \\
\text { results } \\
(\mathrm{N})\end{array}$ & $\begin{array}{l}\text { Err } \\
\text { or } \\
(\mathrm{N})\end{array}$ \\
\hline 1 & 3000 & 0.8 & 0.05 & 4 & 12.02 & 12.60 & $\begin{array}{l}- \\
0.5 \\
8\end{array}$ \\
\hline 2 & 3000 & 0.8 & 0.05 & 4 & 12.02 & 10.90 & +1 . \\
\hline 3 & 3000 & 0.8 & 0.05 & 4 & 12.02 & 08.82 & $\begin{array}{l}12 \\
+3 \\
20\end{array}$ \\
\hline
\end{tabular}

\section{CONCLUSIONS}

Machining parameters used in this study are cutting speed, depth of cut, feed rate and tool flute. Minimum surface roughness optimization obtained in this study is $0.2398 \mu \mathrm{m}$ with corresponding machining parameters, 3000rpm cutting speed, $0.8 \mathrm{~mm}$ depth of cut, 0.05 feed rate and 4 tool flutes. Optimization of machining parameters can be achieved for surface roughness and cutting force simultaneously, either based on surface roughness or cutting force. In this study only surface roughness optimization is verified, the target of the minimum surface roughness is $0.0620 \mu \mathrm{m}$ is selected randomly, but the real value of minimum surface roughness output is $0.2398 \mu \mathrm{m}$ with desirability value 0.000 and corresponding cutting force $12.02 \mathrm{~N}$. Verifications show the error in surface roughness optimization results are more accepted than the corresponding cutting force error. There for Taguchi technique is useful and reliable in optimization techniques.

\section{REFERENCES}

[1] Montgomery, D. C. Introduction to statistical quality control (2nd ed.). New York: Wiley. (1990).
[2] Tan, F. P., \& Creese, R. C. A generalized multi-pass machining model for machining parameter selection in turning. International Journal of Production Research, 33(5), 1467-1487. (1995).

[3] Montgomery, D. C., \& Peck, E. A. Introduction to linear regression analysis (2nd ed.). New York: Wiley. (1992).

[4] Fu, L. , Neural network in computer intelligence. India: Tata Mc Graw Hill Edition. (2003)

[5] Zadeh, L. A., Fuzzy sets and application: Selected papers. R. R. Yager, S Ovchinnikov, M. Tong, \& H. T. Nguyen (Eds.). Evolutionary Computing , 83-98. (1973).

[6] Ross, P. J., Taguchi techniques for quality engineering. New York: McGraw-Hill. (1989).

[7] Montgomery, D. C. Design and analysis of experiment (5th ed.). New York: Wiley. (2001).

[8] Hillier, F. S., \& Liebermann, G. J. Operations research (2nd ed.). Delhi: CBS Publishers and Distributors. (1999).

[9] Goldberg, D. E. Genetic algorithms in search, optimization, and machine learning. Boston, MA: Pearson Education Asia (5th print). (2002).

[10] Glover, F. Tabu search—part II. ORSA Journal on Computing, 2(1), 4 32. (1990a).

[11] Kirkpatrick, K., Gelett, C. D., \& Vecchi, M. P. Optimization by simulated annealing. Sciences, 220, 671-680. (1983).

[12] Hassan, G. A., \& Suliman, S. M. A. Experimental modeling and optimization of turning medium carbon steel. International Journal of Production Research, 28(6), 1057-1065. (1990).

[13] Luong, L. H. S., \& Spedding, T. A. Neural-network system for predicting machining behaviour. Journal of Materials Processing Technology, 52, 585-591. (1995).

[14] Osborne, D. M., \& Armacost, R. L. Review of techniques for optimizing multiple quality characteristics in product development. Computers and Industrial Engineering, 31(1/2), 107-110. (1996).

[15] Dabade, B. M., \& Ray, P. K. Quality engineering for continuous performance improvement in products and processes: A review and reflections. Quality and Reliability Engineering International, 12, 173189. (1996).

[16] Carlyle, W. M., Montgomery, D. C., \& Runger, G. C. Optimization problem and method in quality control and improvement. Journal of Quality Technology, 32(1), 1-17. (2000).

[17] Youssef, H., Sait, S. M., \& Adiche, H. Evolutionary algorithms, simulated annealing and tabu search: A comparative study. Engineering Applications of Artificial Intelligence, 14, 167-181. (2001).

[18] Aggarwal, A.; Singh, H.; Kumar, P.; Singh, M.: Optimizing power consumption for CNC turned parts using response surface methodology and Taguchi's technique, a comparative analysis. Journal of Materials Processing Technology. 200, 373-384 (2008). 